\title{
Paraguay en Un año electoral (2018): trayectorias ECONÓMICAS, POLÍTICAS Y SOCIALES EN LA TRANSICIÓN ENTRE EL GOBIERNO COLORADO SALIENTE Y EL ENTRANTE
}

\author{
Paraguay in 2018: Economic, Political and Social Trends during the \\ Change of Government
}

\author{
MAGDALENA LÓPEZ \\ CONICET/Universidad de Buenos Aires, Argentina
}

\begin{abstract}
RESUMEN
Analizamos una selección de sucesos relevantes para comprender el año 2018 en Paraguay. Las elecciones generales — que confirmaron la hegemonía del Partido Colorado incluso ante la situación de conflicto interno persistente- se constituyeron en su evento central. También rescatamos el acceso de una mujer a la vicepresidencia por primera vez en la historia del país, aunque esto haya sido consecuencia de una estrategia del presidente saliente para asumir su banca de senador activo. En cuanto a la economía, el crecimiento moderado pero mantenido, la inflación controlada y la deuda externa ampliándose dentro de límites claros, dieron al Estado tranquilidad macroeconómica, pese a los grandes problemas por los que atraviesa la región. Respecto a la situación social, la pobreza extrema y total se mantuvieron con relación al año anterior, por lo que se demostró que el desarrollo económico no necesariamente trae mejoras en la calidad de vida.
\end{abstract}

Palabras clave: Paraguay, política, desarrollo económico, escenario social, elecciones generales

\begin{abstract}
This article analyzes the main events that occurred in Paraguay during 2018. First, the general elections confirmed the hegemony of the Colorado Party, even in the unusual situation of internal conflict. Second, a woman was elected vice-president for the first time in the country's recent history. That is a significative political outcome even when it can be interpreted as the outcome of President Cartes' political maneuvering to remain as an active Senator. Third, in 2018, the Paraguayan economy registered controlled inflation, moderate debt growth, and sustained economic growth, which provide macroeconomic stability in the country. Finally, extreme and general poverty remained within the same levels than the previous year. Economic development has not improved the quality of life of the most vulnerable members of Paraguayan's society.
\end{abstract}

Key words: Paraguay, politics, economic development, social scenario, general elections 


\section{INTRODUCCIÓN}

Durante el 2018, el escenario político y social paraguayo estuvo fuertemente marcado por las elecciones generales que renovaron casi la totalidad de los cargos, exceptuando los municipales, que se encuentran desdoblados. El gran ganador de la contienda fue, una vez más, el tradicional Partido Colorado (Asociación Nacional Republicana [ANR]), que logró la presidencia, la mayoría en ambas cámaras del Congreso y la mayoría de las gobernaciones. El año se caracterizó también por el intento político de reparación del tejido social, fuertemente afectado por los enfrentamientos de $2017^{1}$, en torno a la posibilidad de habilitar, por el mecanismo de enmienda, la reelección presidencial. Esto desencadenó una resistencia popular que terminó con la quema del edificio del Senado y con el asesinato, en manos de la represión estatal, de un joven militante el Partido Liberal Radical Auténtico (PLRA o Partido Liberal).

También fue para el Partido Colorado un año complejo, pues su intento del llamado abrazo republicano, es decir, la reunificación del partido detrás del candidato ganador incluyendo las facciones enfrentadas en las elecciones internas, fracasó y se enfrentó al desafío de iniciar un gobierno con el partido oficialista dividido. La disputa entre Horacio Cartes, presidente saliente, líder de la facción Honor Colorado, y Mario Abdo Benítez, presidente entrante, líder de la facción Colorado Añetete, fue un parteaguas del que la ANR no logra reponerse. Tanto en su gestación como en el momento en el que se hizo explícito, el enfrentamiento impregnó la totalidad del espacio político y se volvió el eje de articulación de diferentes actores ${ }^{2}$. Como veremos en este artículo, tanto la proliferación de demandas antes silenciadas, la protección o desprotección de miembros del Congreso, el bloqueo del acceso del presidente saliente a su banca de senador, las tensiones en las gobernaciones, el fin del pacto de impunidad en torno a la corrupción, etcétera, son parte de esta puja.

En cuanto a la estabilidad del régimen, se destacó un proceso de publicación mediática y encausamiento judicial de un amplio entramado de corrupción que involucró a todos los poderes del Estado. Esto desencadenó la renuncia y expulsión de algunos legisladores, así como la masificación de información disponible respecto al estado de cuentas privadas, declaraciones juradas y enriquecimiento ilícito de diferentes funcionarios y miembros del gobierno.

Otro elemento relevante fue la consagración de la primera vicepresidenta mujer de la historia del Paraguay, suceso que se desarrolló en el contexto de la problemática continuidad de Cartes en cargos electivos: quiso pasar de presidente a senador activo, algo prohibido por la Constitución Nacional, que atribuye a los expresidentes una banca pasiva como senador vitalicio.

Se recomienda la lectura de Carrizosa (2018) y González Bozzolasco (2017) para comprender el contexto de estas disputas y enfrentamientos.

Algunas votaciones, declaraciones o decisiones en el Congreso se pudieron predecir a partir del rol que los diferentes actores políticos tuvieron en torno a la disputa colorada interna. 
En este trabajo abordaremos elementos de la política, de la economía y de la sociedad que marcaron el 2018. La selección de hechos para conformar un anuario político suele estar atada a la particularidad de quien realiza esta elección, así como al contexto social en el que se realiza. Entendemos que nuestra selección tiene un sesgo de autor y otro de coyuntura, sumándose el imperativo de la brevedad. Es por esta causa que algunas temáticas quedarán fuera, pese a ser de central importancia, mientras otras serán explicadas con mayor detalle.

\section{EL ESCENARIO POLÍTICO EN UN AÑO ELECTORAL. LA DISPUTA CARTES-ABDO: DEL PARTIDO AL ESTADO}

La relevancia del momento electoral fue acompañada por otros procesos sociopolíticos que marcaron un antecedente en el país, muchos de ellos relacionados con la puja interna de la ANR, que se remonta a procesos previos. Entre algunos fenómenos que influyeron en la agenda pública encontramos la disputa en Ciudad del Este, segundo distrito más importante del país, por los casos de corrupción de los que fueron acusados los miembros del cartista clan Zacarías ${ }^{3}$, elite de gobierno local, que derivó en la destitución de la intendenta y en la activación de mecanismos de sucesión paralelos y superpuestos, entre lo que decidió el Concejo y lo que determinó el Tribunal Superior de Justicia Electoral (TSJE), máxima autoridad en la materia.

Entre el fuego de acusaciones cruzadas, otro factor que desencadenó preocupación fue la aparición de grabaciones que complicaban a Miguel Iturburo Cañete, alto miembro del TSJE. El audio filtrado prometía manipular los resultados de las elecciones a cambio de sumas de dinero. Quien ejercía como jefe de control de Calidad de Informática, fue separado de su cargo en julio de 2018. Sin embargo, el caso opacó la credibilidad de las elecciones, que habían sido, desde un inicio, declaradas fraudulentas por la oposición, para la cual 2018 fue el escenario de la creación de la Alianza Ganar. Los partidos que en 2008 se agruparon en la Alianza Patriótica para el Cambio (APC) reeditaron el itnento de coalición en contra del Partido Colorado pero, esta vez, no lograron triunfar.

La gran multiplicidad de factores que eclosionaron en la coyuntura política estuvo fuertemente marcada por la oposición entre Horacio Cartes, miembro de la ANR, y Mario Abdo Benítez, su correligionario y sucesor presidencial. Este enfrentamiento es también, en parte, resultado de la oposición surgida en torno a la reelección presidencial de 2017. "Una vez concluida la crisis, las mismas facciones políticas que compitieron a favor y en contra de la enmienda fueron las que compitieron en las internas de sus respectivos partidos (Carrizosa 2018:

Los Zacarías son miembros de una misma familia que ejerció el poder político en Ciudad del Este por más de un década. Están acusados de malversación de fondos y otros delitos. Pertenecen a la ANR y su facción es la del expresidente Horacio Cartes. Respecto de ellos, en febrero de 2019, la periodista Griselda Centurión publicó en el diario ABC Color: "El reinado del matrimonio integrado por el senador Javier Zacarías y su esposa Sandra McLeod llegó a su fin luego de años de que la justicia archivara causas en su contra". 
342). En consecuencia, las elecciones generales de 2018 fueron una fotografía del conflictivo proceso que en el Partido Colorado había empezado tiempo atrás.

Consideramos con Cerna y Solis (2018: 262) que los de 2018 "se presentaron como unos comicios de 'disrupción continuista' en los que, como nunca antes - $\mathrm{O}$ al menos no con tanta evidencia - el partido en el gobierno logró su permanencia en el poder, pero con una fractura enorme entre las corrientes internas del nuevo presidente Mario Abdo Benítez (Colorado Añeteté) y el mandatario saliente Horacio Cartes (Honor Colorado)".

Mario Abdo Benítez, miembro de una familia de estirpe colorada e hijo del secretario privado de Stroessner, encarnó las políticas de la ANR desde una posición tradicionalista y conservadora, en contraposición a la del "empresario advenedizo" que representaba Cartes ${ }^{4}$ para esta vertiente del partido, además del candidato Peña ${ }^{5}$, quien había sido del Partido Liberal hasta muy poco tiempo antes de la presentación de candidaturas.

Este enfrentamiento va a atravesar problemáticas en diferentes niveles de los poderes Ejecutivo y Legislativo. A partir de esto, los conflictos surgidos en instancias subnacionales (gobernaciones y municipios) se convirtieron en una caja de resonancia. Los diferentes líderes de ambas facciones agudizaron sus intervenciones e, incluso dentro del Congreso, los miembros de otros partidos fueron asociados a una u otra línea, a partir de cómo votasen o de los argumentos que diesen.

Si bien el enfrentamiento fue especialmente agudo previo a las elecciones, y existió un intento de ritual de abrazo republicano ${ }^{6}$ para triunfar con una lista unificada, el proceso fracasó y pudo plasmarse cuando Cartes retira su renuncia, argumentando en su cuenta oficial de Twitter: "Veo con gran pena que algunos legisladores no desean que se cumpla la voluntad popular del 22 de abril, por lo que retiro mi renuncia al cargo de presidente de la República. Lamento que entre colorados no pudimos llegar con una bancada unida al próximo período" (@Horacio_Cartes, 26 de junio de 2018).

El retiro de la renuncia de Cartes por la imposibilidad de lograr para ella aceptación parlamentaria, bloqueó su plan de acceder a la banca activa del Senado y truncó el acceso a la presidencia de una mujer, por primera vez en la historia del Paraguay, tal como desarrollaremos a continuación.

Respecto a la mutación del rol de Horacio Cartes dentro de la ANR, recomendamos la lectura de Lachi (2018). Santiago Peña fue ministro de Hacienda de Horacio Cartes. Con una formación académica avanzada y experiencia en el mundo privado, Peña tuvo que convertirse al Partido Colorado, en un ritual en el que recibió el pañuelo públicamente, para dejar atrás su cercanía al PLRA.

Sobre esta estrategia de acercamiento luego de haber hecho su campaña a partir de una abierta oposición, Pérez Talia (2018: 48) sostuvo: "Pero cuando Abdo Benítez triunfó y se convirtió en el candidato oficial del Partido Colorado, su discurso dio un giro repentino, abandonó su posición crítica del oficialismo y se mostró muy cercano al presidente Cartes. Tomó esa decisión ante la disyuntiva que le plantearon dos escenarios: mantenerse coherente con su discurso de campaña, a distancia prudencial de Cartes y su entorno, pero a sabiendas de que ello disminuiría sus posibilidades en las elecciones, o apartarse de su discurso y buscar el célebre 'abrazo republicano', todo un ritual dentro del coloradismo". 
El nombramiento por parte del presidente triunfante de funcionarios exclusivamente ajenos al círculo del presidente saliente, marcó otro hito en el fin del abrazo republicano. En su discurso de asunción al cargo, Abdo Benítez referenció, sin nombrarlo, a Cartes: “En Paraguay no ganó el que tenía más dinero, el que tenía más estructura, ganó el que nunca perdió la fe". Claro que, además, dijo que su jefe de campaña era Dios y que él prefiere más "los aplausos de salida que los de entrada" (Abdo Benítez 2018). A continuación, revisaremos dos momentos políticos conectados con la disputa entre los presidentes.

En primer lugar, el problema surgido tras la renuncia del vicepresidente saliente que desembocó en el acceso de una mujer a la vicepresidencia, por primera vez en la historia del Paraguay. En segundo, el proceso judicial y el escándalo político por el descubrimiento de un entramado de corrupción que incluía a miembros de los tres poderes y salpicaba a los partidos tradicionales.

\section{Una mujer a la vicepresidencia por un pacto entre caballeros}

La Constitución Nacional (cN) de Paraguay, en su artículo $229^{7}$, prohíbe bajo todo concepto la reelección presidencial. Los presidentes salientes son beneficiados con una banca vitalicia en el Senado, con voz y sin voto, tal como establece la CN en su artículo $189^{8}$. Solo serán excluidos de este espacio legislativo aquellos que hayan sido removidos por medio de un juicio político.

Para poder ejercer un cargo electivo parlamentario, posterior a haber sido el vicepresidente durante todo el gobierno de Horacio Cartes, Juan Afara presentó su renuncia en marzo, de manera de candidatearse en abril como senador. El Congreso la aceptó, dejando vacante el cargo de vicepresidente. A pesar de que la Carta Magna es clara respecto a los seis meses de anterioridad, en el caso de Afara la renuncia se efectivizó apenas un mes antes.

El presidente Cartes también lanzó su candidatura a senador, resistida por algunos parlamentarios y líderes políticos, así como la del expresidente Nicanor Duarte Frutos ${ }^{9}$. Sin embargo, una decisión de la Corte respaldó la candidatura

7 El artículo 229 expresa: “El Presidente de la República y el Vicepresidente durarán cinco años improrrogables en el ejercicio de sus funciones, a contar desde el quince de agosto siguiente a las elecciones. No podrán ser reelectos en ningún caso. El Vicepresidente solo podrá ser electo Presidente para el período posterior, si hubiese cesado en su cargo seis meses antes de los comicios generales. Quien haya ejercido la presidencia por más de doce meses no podrá ser electo Vicepresidente de la República" (Artículo 229. De la duración del mandato. Constitución Nacional de Paraguay, 1992).

$8 \quad$ Cita el artículo 189: “Los ex presidentes de la República, electos democráticamente, serán senadores vitalicios de la Nación, salvo que hubiesen sido sometidos a juicio político y hallados culpables. No integrarán el quórum. Tendrán voz pero no voto" (Artículo 189. De las senadurías vitalicias. Constitución Nacional de Paraguay 1992).

9 Nicanor Duarte Frutos fue presidente del Paraguay entre 2003 y 2008. Pertenece al Partido Colorado y en las disputas internas apoyó a la facción de Colorado Añetete. Fue nombrado por Mario Abdo Benítez como director de la Entidad Binacional Yacyreta. Al finalizar su mandato, en 2008, Duarte Frutos tuvo también problemas para asumir su bancada y la maniobra no fue permitida. En 2018 volvió a tener el mismo problema. Su caso fue más difundido que el del reciente presidente Cartes, puesto que incluso llegó a asistir 
de ambos. Para el 9 de mayo, por propuesta de la presidencia y con la aprobación de 27 senadores y 54 diputados (81 votos en total entre ambas cámaras), accedió a la vicepresidencia Alicia Pucheta de Correa, primera mujer en llegar a ejercer un cargo máximo en el Ejecutivo Nacional. Su carrera estuvo principalmente marcada por haber sido ministra de la Corte Suprema, desde donde avaló las candidaturas a senadores de Cartes y Duarte Frutos.

La estrategia política implicaba que, tras la presentación y aceptación de renuncia de Afara, se nombrase un vice que, posteriormente, al renunciar Cartes para asumir la banca que ganó en las elecciones de abril, sería presidente por sucesión. Con la renuncia de Afara y el nombramiento de Pucheta, solo restaba que se retire el presidente. Por ello, el 28 de mayo de 2018, Horacio Cartes elevó su renuncia ${ }^{10}$ al presidente del Senado, Fernando Lugo Méndez. En el documento oficial, Cartes afirmaba que lo hacía para cumplir con la decisión democrática y popular de ejercer su cargo como senador.

Sin embargo, tras la falta de quórum y la resistencia parlamentaria a tratar el pedido del presidente de ser desafectado de su cargo, fue Horacio Cartes quien decidió retirar su propia renuncia el 26 de junio de $2018^{11}$.

El día de la toma de banca de los nuevos congresales, ninguno de los expresidentes pudo jurar, a excepción de Fernando Lugo, quien se amparó en el artículo 189 de la CN y argumentó que su banca podía ser activa pues no estaba sujeto a la senaduría pasiva por haber sido removido por juicio político.

Por la articulación de poderes, las internas del coloradismo y la oposición de los demás partidos, la estrategia cartista no pudo ser desarrollada. La experiencia del acceso de una mujer a la vicepresidencia se asemejó más a un acuerdo (fallido) entre caballeros que al emergente de una movilización feminista y la demanda por mayor participación y representación política de mujeres ${ }^{12}$.

Alicia Pucheta cumplió un mandato muy corto. Fue la primera mujer en la historia del país en llegar a ese cargo, no por votación popular, sino por la activación de un mecanismo sucesorio. En resumen: su acceso a la presidencia no se constituyó en un símbolo de madurez democrática, sino en la cristalización de un intento inconstitucional de acceso al Senado por parte del presidente

al nombramiento de los nuevos congresales. En dicha instancia,, parado a un lado de la senadora que lo reemplazó, hizo la mímica del ritual de jura.

10 "Me dirijo a Vuestra Honorabilidad, en virtud de la disposición del Artículo 202, inciso 16 de la Constitución, para presentar mi renuncia al cargo de presidente de la República del Paraguay, que vengo ejerciendo por voluntad popular desde el 15 de agosto de 2013. He adoptado esta determinación para dar cumplimiento a la decisión democrática del pueblo expresada en las urnas el pasado 22 de abril, que me eligió para el cargo de Senador de la Nación para el período 2018 /2023, habiendo sido proclamado en tal carácter por el Tribunal Superior de Justicia Electoral" (Cartes, mayo de 2018).

11 "Me dirijo a Vuestra Honorabilidad para retirar mi renuncia al cargo de Presidente que he presentado en fecha 28 de mayo y que no ha tenido tratamiento en el Congreso Nacional" (Cartes, junio de 2018).

12 Esta demanda existe e, incluso, se han articulado acciones multipartidarias en torno a ella, pero no ha logrado aún concretarse en la llegada de una mujer a un alto cargo del Ejecutivo nacional. 
saliente. En su corto paso por el poder no ejerció un liderazgo significativo ni desarrolló estrategias para ejercer, con posterioridad, otro cargo electivo.

\section{Corrupción y tráfico de influencias: la justicia atraviesa la política}

Entre 2017 y 2018, múltiples entramados de corrupción en varios poderes comenzaron a deshilvanarse y hacerse públicos. Quizás la persona más visiblemente involucrada fue el senador González Daher, de la facción cartista del Partido Colorado, quien ejercía el cargo de presidente del Jurado de Enjuiciamiento de Magistrados. Fue acusado en 2017 de tráfico de influencia, asociación criminal y cohecho pasivo agravado, a partir de la filtración de un conjunto de audios que demostraban la existencia de una aceitada red de corrupción y la entrega de beneficios políticos y judiciales a cambio de dinero.

Pero este descubrimiento no fue el único. También salieron a la luz reportes de gastos inexplicables por parte de congresales, así como contrataciones de lujo financiadas con dinero público (los casos se popularizaron como "niñera de oro", "jardinero de oro", etcétera). Un ejemplo de esto fue el diputado José María Ibáñez, imputado por el caso "caseros de oro". Sin embargo, a pesar de confesar el delito Ibáñez no perdió su investidura, sino que fue salvado por su Cámara. Meses más tarde tuvo que renunciar por presión popular.

En un contexto latinoamericano de judicialización de la política, el tratamiento de los casos descubiertos buscó tener, en el escenario paraguayo, una resolución política. Es por esto que el Senado debatió respecto a las medidas a tomar con sus miembros involucrados. Las decisiones fueron disímiles y no marcaron un patrón institucional coherente. Para el caso de González Daher, la Cámara de Senadores primero lo protegió, luego rechazó su renuncia y finalmente decidió destituirlo. Por su parte, Oviedo Matto, miembro del PUNACE ${ }^{13}$, atravesó un proceso más corto: presentó su renuncia y esta fue aceptada.

Los casos de corrupción y abuso de poder que se destaparon generaron una ola de protestas sostenidas en el tiempo, organizadas en una especie de rally que incluía manifestaciones y escraches a funcionarios en sus viviendas. Si bien no fueron masivas ni multitudinarias, su persistencia y permanencia las convirtió en un fenómeno atendible, que movilizó a la población. En 2018, González Daher entró nuevamente al Senado por ocupar el tercer lugar en la lista cerrada y bloqueada colorada, encabezada por Horacio Cartes, la más votada en las elecciones.

A pesar de no haber transcurrido ni un año de su remoción, González Daher juró nuevamente como senador en junio de 2018, para renunciar unos meses

13 PUnAce (Partido Unión Nacional de Ciudadanos Éticos) es el partido del ex líder colorado Lino Oviedo, que rompió con la ANR y fundó su propia agrupación. En algunas elecciones llegó a ser tercera fuerza electoral. Desde que murió su fundador en 2013, el partido se encuentra en escalonada extinción. 
después como resultado de las protestas en su contra. A fines de septiembre de 2018 fue puesto, con su hijo, en prisión preventiva.

El éxito de las manifestaciones no radicó en desarticular todas las redes de corrupción, pero sí en visibilizar el pacto de impunidad y en presionar para gestar las renuncias, además de revitalizar el pedido de desbloqueo de listas completas cerradas (sábanas), solicitud que aparece cíclicamente reeditada en el debate público.

Por ejemplo, en septiembre de 2011 el Senado rechazó una propuesta de ley que apuntaba a eliminar las listas sábanas. En el 2014 fue muy fuerte la organización de la Asociación Fuera Lista Sábana del Paraguay, que se articuló en torno a esta demanda y acompañó el proyecto presentado por Blas Llano titulado "QUe MODIFICA LOS ARTí́culOS $1^{\circ}, 2^{\circ}, 3^{\circ}$ Y AMPLÍA LA LeY No. 4584/12...", que sostenía que senadores, diputados, juntas departamentales y parlamentarios del Mercosur "serán elegidos por el sistema de representación proporcional, en listas desbloqueadas, completas o no". El proyecto no prosperó y la organización sigue vigente, aunque con menos presencia.

En2018, elPartidoPatria Querida ( $\mathrm{PPQ}$ ) presentóotro proyectodevoto preferencial y desbloqueo de listas sábanas, pero asociado a la implementación de urnas electrónicas. Luego, el senador Cubas, de Cruzada Nacional, presentó en 2019 su propio proyecto que, a diferencia del de $\mathrm{PPQ}$, no contempla incorporación de urnas tecnológicas ${ }^{14}$. El primero fue aceptado en 2019; el segundo, rechazado. El tema será parte de la reforma electoral que se planea realizar durante el gobierno de Abdo Benítez, que incluirá también el debate sobre la reelección, el financiamiento de la política y la agudización de controles sobre los resultados electorales. En septiembre de 2018 se realizó, bajo convocatoria del Ejecutivo, las primeras reuniones para modificar el Código Electoral, Ley 834 de 1996.

La disputa de facciones y su repercusión en diferentes ámbitos se extendió también a la justicia, sin embargo, en algunos casos la corrupción y el enriquecimiento fueron tan burdos, que la presión popular forzó un desenlace que no se habría logrado en las cámaras por la activación de mecanismos de protección y bloqueo.

Las elecciones cambiaron la facción del Partido Colorado que estaba a cargo de la presidencia y renovaron algunos escaños, aunque muchas de ellas permanecieron en las mismas manos. De hecho, entre 1993 y 2023 (año en el que terminarán su período los congresales elegidos en 2018) más de la mitad de las bancas de ambas Cámaras fueron atribuidas a las mismas personas y en algunos

14 El proyecto cuenta con un solo artículo en el que solicita que se modifique el artículo 258 de la Ley 834/96 para que consigne que todos los cargos electivos grupales (convencionales constituyentes, senadores y diputados nacionales, parlamentarios del Mercosur, miembros de las Juntas Departamentales y municipales), tanto en internas como en elecciones generales, "serán electos directamente por medio de listas abiertas donde el elector podrá modificar el orden de ubicación de todos o de cualquier candidato. Del mismo modo se hará con los candidatos suplentes" (Cubas 2018). 
casos la permanencia en el cargo alcanzó los seis períodos ${ }^{15}$. A continuación, revisaremos los resultados de la contienda electoral haciendo hincapié en las elecciones presidenciales, legislativas y de gobernadores.

\section{LAS ELECCIONES GENERALES DE 2018}

La resolución de la interna colorada a favor de Mario Abdo Benítez dejó de manifiesto el retorno a los caudillos partidarios, una retórica más de la pertenencia y tradicionalidad del partido que de la innovación y el recambio. En el triunfo de esta retórica fue igual de necesaria la apelación a la ascendencia familiar de Abdo y su probada pertenencia histórica al partido, como su alianza estratégica con otros caudillos de la ANR, importantes a nivel regional y para la construcción legislativa. El candidato perdedor de las internas, Santiago Peña, migró hacia la actividad privada como asesor de los bancos de su mentor, Horacio Cartes, quien volcó su campaña a la propuesta legislativa, encabezando una lista de senadores.

El PLRA llegó a las elecciones encabezando, como en 2008, una alianza estratégica con los sectores luguistas y un pequeño conjunto de partidos minoritarios. Esta fórmula invirtió la triunfante de 2008, dado que dejó la presidencia al liberal Efraín Alegre y la vicepresidencia al progresista Leonardo Rubín, del Frente Guasu. La Alianza Ganar no se presentó como coalición a todos los cargos, repitiendo la estrategia de separarse en las legislativas, donde el PLRA sigue siendo, como históricamente, el segundo partido con mayor concentración de bancas.

Las elecciones generales se realizaron el 22 de abril de $2018^{16}$. Se votaron un presidente $\mathrm{y}$ un vicepresidente, cuarenta y cinco senadores titulares y treinta suplentes, ochenta diputados titulares y ochenta suplentes, diecisiete gobernadores y diecisiete juntas departamentales ${ }^{17}$. Analizaremos brevemente los resultados.

\section{La competencia por el Poder Ejecutivo}

La oferta electoral para cubrir la presidencia y la vicepresidencia fue de diez fórmulas. De las diez candidaturas a la presidencia y diez a la vicepresidencia, solo una estuvo ocupada por mujeres ${ }^{18}$. Todos los presidenciables fueron varones, para todos los partidos. La edad promedio de los candidatos fue

15 Es el caso del colorado Juan Carlos Galaverna, quien, el 9 de mayo de 2019 fue homenajeado por sus 30 años de labor parlamentaria ininterrumpida.

16 Se recomienda la lectura de Solís Delgadillo y Cerna Villagra (2019) para analizar las elecciones de 2018 a partir de una lectura de la ciencia política.

17 En rigor de la extensión de este trabajo, exceptuaremos el estudio de las juntas departamentales.

18 Solo para el cargo de vicepresidente, el Partido del Movimiento Patriótico Popular (PMPP) contó con una candidata mujer. 
aproximadamente de cincuenta y siete años. Es importante mencionar que el electorado paraguayo tiene una gran condensación de votantes jóvenes por la conformación poblacional actual del país, que atraviesa su bono demográfico.

Tabla 1. Candidatos a presidente y vicepresidente en las elecciones generales según lista, partido y edad (2018)

\begin{tabular}{|c|c|c|c|}
\hline LISTA & PARTIDo & Presidente y Vicepresidente & EDAD \\
\hline \multirow[t]{2}{*}{1} & ANR & Mario Abdo Benítez & 46 \\
\hline & & Hugo Adalberto Velázquez Moreno & 50 \\
\hline \multirow[t]{2}{*}{5} & Ganar & Pedro Efraín Alegre Sasiain & 55 \\
\hline & & Hermes Leonardo Rubín Godoy & 51 \\
\hline \multirow[t]{2}{*}{12} & PFA & Pedro Almada Galeano & 58 \\
\hline & & Carlos Raúl Galeano Perrone & 58 \\
\hline \multirow[t]{2}{*}{15} & MNAP & Jaro Ilicineo Anzoategui Mariño & 56 \\
\hline & & José Aníbal Cabello Medina & 43 \\
\hline \multirow[t]{2}{*}{22} & $\mathrm{SN}$ & Efraín Enríquez Gamon & 86 \\
\hline & & Juan Bernardino Méndez Vall & 70 \\
\hline \multirow[t]{2}{*}{23} & PVP & Juan Bautista Ybañez & 73 \\
\hline & & Cantalacio Salvador Invernizzi Otazu & 64 \\
\hline \multirow[t]{2}{*}{30} & MRP & Ramons Ernesto Benítez Amarilla & 56 \\
\hline & & Carlos Miguel Eusebio Duarte Torres & 65 \\
\hline \multirow[t]{2}{*}{45} & PSDH & Justo Germán Ortega Maqueda & 56 \\
\hline & & Juan Roberto Velázquez Rotela & 38 \\
\hline \multirow[t]{2}{*}{50} & PMPP & Atanasio Galeano & 57 \\
\hline & & Irma Vera de Viera & 51 \\
\hline \multirow[t]{2}{*}{60} & Unamonos & Celino Ferreira Sanabria & 59 \\
\hline & & Juan Carlos Giménez Ferreira & 57 \\
\hline
\end{tabular}

Fuente: elaboración propia a partir de datos del Tribunal Superior de Justicia Electoral (TSJE)

Con una participación del 61,25\% de los electores habilitados (2 597989 de 4241 507), el triunfo fue para Mario Abdo Benítez y Hugo Velázquez, con el $46,42 \%$ de los votos. Mario Abdo Benítez es el presidente más joven de la democracia paraguaya. A pesar de haber existido diez listas, solo dos tuvieron real oportunidad de ganar. La ANR y la AG sumaron $89,18 \%$ del caudal electoral. Las demás, todas juntas, concentraron apenas el 5,65 \% de los votos, número similar al obtenido sumando votos blancos y nulos, como puede verse en la tabla 2. 
Tabla 2. Distribución del voto en elección de presidente y vicepresidente, con votos blancos y nulos (2018)

\begin{tabular}{lrr}
\hline & \multicolumn{1}{c}{ Vото } & \multicolumn{1}{c}{$\%$} \\
\hline ANR & 1206067 & 46,42 \\
Alianza ganar & 1110464 & 42,74 \\
Resto de las listas & 146910 & 5,65 \\
Votos nulos & 71924 & 2,77 \\
Votos en blanco & 62624 & 2,41 \\
\hline Total & 2597989 & 100,00 \\
\hline
\end{tabular}

Fuente: elaboración propia a partir de datos del Tribunal Superior de Justicia Electoral (TSJE)

Los únicos departamentos donde los candidatos de la ANR perdieron y se impusieron los de Ganar fueron: Concepción, Cordillera, Alto Paraná y Central. A estos se les sumó el distrito Exterior.

Si comparamos el porcentaje de votos obtenido por la ANR entre 2018 y 2013, podemos observar que amplió su apoyo de $45,80 \%$ a $46,42 \%$. Coincidimos con Cerna y Solís (2018: 270) en que esto confirma el "crecimiento paulatino de la ANR tras la derrota de 2008 y su capacidad para realinear al electorado paraguayo y aumentar su caudal electoral $[\ldots] "$.

Las elecciones no tuvieron aceptación automática y las denuncias de fraude e irregularidades fueron numerosas por parte de los partidos de la oposición. A pesar de esto, el TSJE revisó las actas y dio por confirmados los resultados finales.

\section{La contienda legislativa}

El Congreso paraguayo volvió a quedar conformado mayoritariamente por el Partido Colorado, que obtuvo diecisiete escaños en senadores y cuerente y dos en diputados, contra la primera minoría del PLRA-Alianza Ganar con trece senadurías y treinta bancas en diputados. El resto se distribuyó entre diferentes partidos más pequeños, que lograron, en algunos casos, mejorar su desempeño.

En cuanto a la cantidad de partidos que accedieron a bancas en las cámaras, encontramos que en Senadores se incrementó de siete organizaciones a ocho, mientras que en Diputados se disminuyó de ocho a siete ${ }^{19}$. En una comparación interperíodos como la observable en la tabla 3, podemos notar que, en la Cámara de Senadores, la ANR perdió dos bancas comparando con la elección general

19 Esta variabilidad llevó a que Solís Delgadilllo y Cerna Villagra (2019: 276) sostengan: “al capturar el número efectivo de partidos parlamentarios (NEPP) se puede dar cuenta de que este indicador ha oscilado entre el bipartidismo y un discreto pluralismo de tres partidos efectivos". Sin embargo, remarcamos que los terceros partidos siguen siendo muy minoritarios en cuanto a bancas comparados con los dos tradicionales. 
de 2013, pero aún no alcanzó el número más bajo: quince escaños en 2008. En Diputados también disminuyó dos. Su opositor, el tradicional PLRA, mantuvo la misma cantidad de senadores en las elecciones de 2013 y las de 2018.

Dos partidos nuevos irrumpieron en ambas cámaras: Hagamos ${ }^{20}$ y Cruzada Nacional. El primero logró dos escaños en Senadores y en Diputados, el segundo uno en cada una. Son interesantes estos elementos porque Hagamos se construyó como un partido novedoso, con una campaña política centrada en medios digitales y redes sociales, mientras que Cruzada Nacional se forjó en torno a la figura del excolorado Paraguayo Cubas. Desde el inicio del gobierno de Abdo, Hagamos no ha sorprendido en las votaciones ya que ha sido un partido subsidiario de los tradicionales, acompañando sus propuestas.

En cambio, Cubas, conocido por sus polémicas intervenciones, ha logrado renombre por protagonizar enfrentamientos con sus colegas, golpes con cintos, agresiones verbales y discursos fuertes en contra de las elites políticas, que tienen una llegada muy extendida en ciertos sectores de la población ${ }^{21}$. Payo Cubas estructura sus intervenciones en torno a anular la mediación de la representación ${ }^{22}$ y hablar "por el pueblo", denunciando al Poder Legislativo y las dinámicas de impunidad, corrupción y encubrimientos que se dan en la clase política. Esto lo hace acompañado con discursos en contra de sus pares, muy homofóbicos y, muchas veces, de tinte conservador ${ }^{23}$.

El Partido Patria Querida, que venía de una muy mala elección en el $2013^{24}$, logró recuperar tres bancas en cada cámara a partir de la figura de Fidel Zabala, un ganadero que fue secuestrado por el Ejército del Pueblo Paraguayo y entregado vivo noventa y cuatro días después. Los resultados parecerían indicar que la ANR logró atravesar la disputa entre sus facciones y reponerse como una maquinaria electoral muy exitosa en la concentración de votos.

20 Los dos líderes de Hagamos, Tony Apuril (que logró una senaduría) y Tito Ibarrola (con una banca de diputado), conforman un grupo de comediantes asociados al entretenimiento humorístico y mediático. Su llegada a la política fue resultado, entre otros elementos de retórica de transparencia y diferenciación del resto de la elite, de la capitalización de su popularidad previa.

21 Suele solicitar que las votaciones sean nominales para que cada senador diga en voz alta su postura. Ha solicitado que no se sesione a puertas cerradas, al contrario, que todas las sesiones sean abiertas. En cierta forma, se muestra como quien "desenmascara" a sus pares, los expone para marcar sus diferencias.

22 Para un análisis más a largo plazo del problema de la representación en la democracia paraguaya: López $(2017,2018)$.

23 Por lo reciente del fenómeno Cubas, no existen aún trabajos académicos que aborden la temática, pero sí han proliferado columnas de opinión periodística y ensayos referidos al tema. Acceder a: Ruiz Díaz (2018) y Duarte Penayo (2018).

24 Para más información de las elecciones de 2013, recomendamos la lectura de Turner (2014) y López (2018). 
Tabla 3. Conformación de Cámara de Senadores y Diputados según partidos y cantidad de bancas $(2008,2013$ y 2018)

\begin{tabular}{|c|c|c|c|c|c|c|}
\hline & \multicolumn{2}{|c|}{2008} & \multicolumn{2}{|c|}{2013} & \multicolumn{2}{|c|}{2018} \\
\hline & Senadores & Diputados & Senadores & Diputados & Senadores & Diputados \\
\hline ANR & 15 & 30 & 19 & 44 & 17 & 42 \\
\hline PLRA & 14 & $27^{*}$ & 13 & 27 & 13 & 17 \\
\hline UNACE & 9 & 15 & 2 & 2 & 1 & - \\
\hline PPQ & 4 & 3 & - & 1 & 3 & 3 \\
\hline PDP & 1 & 1 & 3 & - & 2 & - \\
\hline PPT & 1 & 1 & - & - & - & - \\
\hline PPS & 1 & - & - & - & - & - \\
\hline APC & - & 2 & - & - & - & - \\
\hline $\mathrm{ADB}^{* *}$ & - & 1 & - & - & - & - \\
\hline PEN & - & - & 1 & 2 & - & 2 \\
\hline AP & - & - & 2 & 2 & - & - \\
\hline FG & - & - & 5 & 1 & 6 & - \\
\hline $\mathrm{PCH}$ & - & - & - & 1 & - & - \\
\hline Ganar & & & & & & $13^{* * * *}$ \\
\hline Hagamos & - & - & - & - & 2 & 2 \\
\hline $\begin{array}{l}\text { Cruzada } \\
\text { Nacional }\end{array}$ & - & - & - & - & 1 & 1 \\
\hline Total & 45 & 80 & 45 & 80 & 45 & 80 \\
\hline
\end{tabular}

*En trabajos previos señalamos que los escaños del PLRA eran 29, esto se debe a la doble pertenencia de los representantes elegidos, como el caso de Víctor Ríos Ojeda, quien pertenece a la Alianza Patriótica para el Cambio y, a la vez, es miembro de la Bancada del Partido Liberal.

**Alianza Departamental Boquerón fue un partido del departamento de Boquerón ${ }^{25}$.

***Algunos candidatos del PLRA se presentaron en algunos distritos como Alianza GANAR, razón por la cual en las elecciones de 2018 su número de bancadas aparece disminuido, ganando relevancia Ganar.

Fuente: elaboración propia a partir de datos del Tribunal Superior de Justicia Electoral (TSJE) 26

Respecto de la conformación de género de ambas cámaras, el resultado es desalentador. De las 45 senadurías titulares, ocho están en manos de mujeres (dos de la ANR, una del PDP, una del PPQ, tres del PLRA y una del FG). De los 80 escaños para diputados titulares, doce son ocupados por mujeres (cinco de la ANR, dos de Ganar, dos del PLRA, una del PPQ y dos del PEN). La masculinización de ambas cámaras es muy marcada, lo cual reafirma la necesidad de tomar

25 Para más datos sobre las elecciones a nivel departamental y las preferencias sobre estas agrupaciones, recomendamos la lectura de Duarte Recalde (2013); respecto a la nacionalización de las agrupaciones departamentales, referimos a Solís Delgadillo y Cerna Villagra (2019).

26 Para las elecciones de 2008 se utilizó de fuente la publicación oficial de Resultados de las Votaciones Generales (2008= disponibles en https://www.tsje.gov.py/e2008/pdf/2008_resultados.pdf). 
medidas que generen espacios propicios para la participación de mujeres en política, tanto dentro de los partidos como en las listas para cargos electivos.

El Código Electoral, en el capítulo V, artículo 32, apartado q, refiere que lo partidos deben garantizar:

los mecanismos adecuados para la promoción de la mujer en los cargos electivos en un porcentaje no inferior al veinte por ciento y el nombramiento de una proporción significativa de ellas en los cargos públicos de decisión. A los efectos de garantizar la participación de la mujer en los cuerpos colegiados a elegirse, su postulación interna como candidatas deberá darse razón de una candidata mujer por cada cinco lugares en las listas, de suerte que este estamento podrá figurar en cualquier lugar pero a razón de una candidata por cada cinco cargos a elegir. Cada partido, movimiento o alianza propiciador de lista queda en libertad de fijar la precedencia (Código Electoral Paraguayo. Ley No. 834/96).

La presencia de menos de 18\% de mujeres en Senadores y 15\% en Diputados demuestra que Paraguay no cumple con su cupo legal del 20\%, que, además, es considerado ineficiente y muy escaso como porcentual obligatorio de participación femenina.

Gráfico 1. Distribución de bancadas según sexo en ambas cámaras. Elección general (2018)

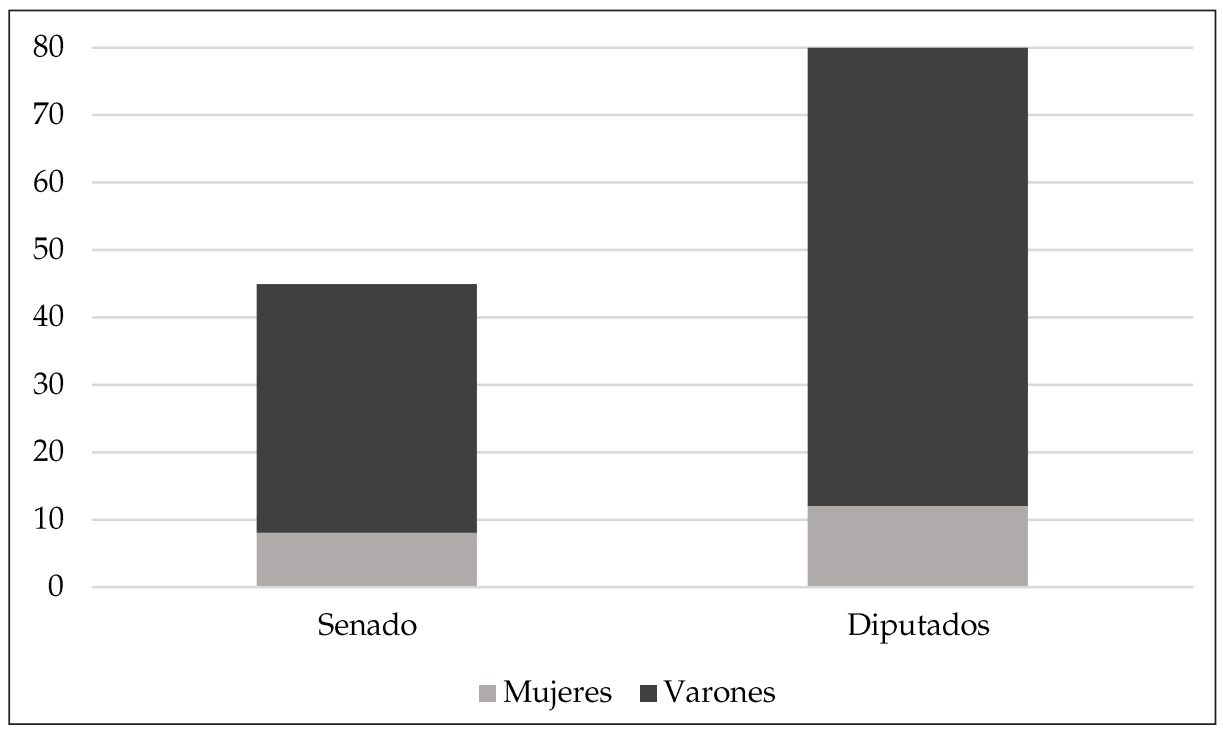

Fuente: elaboración propia a partir de datos del Tribunal Superior de Justicia Electoral (TSJE) 
Con la intención de solventar el problema de la subrepresentación femenina, en marzo de 2018 la Cámara de Senadores aprobó, con treinta y dos votos, la Ley de Paridad Democrática, que establecía un cupo obligatorio de $50 \%$ de mujeres en las listas para las internas de los partidos. La propuesta determinaba que las mujeres y los varones debían estar intercalados y que las listas finales se conformarían a través del sistema D’Hondt, vigente en la actualidad.

Alllegar a la Cámara de Diputados en junio, la ley fue completamente modificada y todos los artículos que indicaban la paridad del $50 \%$ fueron amputados, dando como resultado un documento más propositivo que alentaba genéricamente medidas para igualar la participación de mujeres, pero no explicitaba cómo hacerlo. Los discursos de los diputados incluyeron un conjunto de argumentos que atentaban contra los derechos de las mujeres y de la diversidad sexual. De hecho, algunos sostuvieron que esta ley era la puerta de entrada al matrimonio entre personas del mismo sexo y del acceso al aborto legal ${ }^{27}$.

Retornando a la cámara originaria en septiembre, fue ratificada la versión inicial del Senado, que garantizaba la participación femenina y masculina igualitaria. La ley volvió a la cámara baja en octubre, donde, con una mayoría de cincuenta y dos votos por la versión de Diputados, se impuso la ley de Paridad sin paridad, que incentivaba la capacitación y la formación de líderes mujeres, sin garantizar un cupo de acceso igualitario. En noviembre de 2018, mediante el Decreto 596/18, Mario Abdo Benítez vetó la ley de Paridad (en la versión de la Cámara de Diputados) por considerarla inocua, no funcional con los fines que plantea e imprecisa, dando por finalizado su tratamiento.

\section{La elección de gobernadores}

Las gobernaciones fueron mayoritariamente obtenidas por los candidatos colorados. En Alto Paraguay, Alto Paraná, Boquerón, Caazapá, Canindeyú, Central, Guairá, Itapúa, Misiones, Neembucú, Paraguarí, Presidente Hayes y San Pedro se impusieron gobernadores de la ANR. En Concepción, Cordillera y Amambay triunfaron líderes liberales, y en Caaguazú, uno de la Alianza Ganar. Esto reforzó un magro triunfo del Partido Colorado, que había entablado relaciones con diversos líderes para sumarlos a la lista 1.

Como sostienen Solís Delgadillo y Cerna Villagra (2019), uno de los elementos más remarcables de esta estrategia es el triunfo en el Departamento Central, que

$27 \quad$ Si bien la relación no existía, nos resulta interesante revisar cómo el clima regional de opiniones fuertemente religiosas y que atacan las libertades personales, tomó en Paraguay un cariz diferencial: no llegó de la mano de partidos religiosos pentecostales, como en los demás países del área, sino que ya existía dentro de las elites de gobierno y parlamentarias de ambos partidos tradicionales. De hecho, opiniones como estas, sumadas al tradicional anticomunismo, suelen aparecen reiteradamente en discursos públicos desde el inicio de la transición. A diferencia de otros países, no hay una irrupción de una nueva creencia ni de un actor político-religioso diferenciado, sino que son ideas en circulación y reedición constante (muchas impregnadas durante los 35 años del stronismo), difundidas por los sectores conservadores de los partidos tradicionales. 
había sido desde 1998 epicentro del poder liberal y ahora en manos coloradas, con un candidato de la facción cartista.

En algunos casos, la diferencia de votos fue muy pequeña e, incluso, se prestó a denuncias de fraude y sospechas. En la siguiente tabla podemos observar los primeros y segundos resultados por distrito y la fuerza política y nombre del gobernador electo.

Tabla 4. Porcentaje de votos a las dos primeras fuerzas por departamento y gobernador electo

\begin{tabular}{|c|c|c|c|}
\hline DEPARTAMENTO & PARTIDO & \% vото & GOBERNADOR ELECTO \\
\hline \multirow{2}{*}{ Concepción } & PLRA & 49,67 & \multirow{2}{*}{ - Edgar Idalino López Ruiz (PLRA) } \\
\hline & ANR & 41,02 & \\
\hline \multirow{2}{*}{ San Pedro } & ANR & 39,57 & \multirow{2}{*}{ - Carlos Alcibiades Giménez Díaz (ANR) } \\
\hline & Ganar & 34,14 & \\
\hline \multirow{2}{*}{ Cordillera } & PLRA & 45,03 & \multirow{2}{*}{ - Hugo Alberto Fleitas Ovelar (PLRA) } \\
\hline & ANR & 44,75 & \\
\hline \multirow{2}{*}{ Guaira } & ANR & 58,23 & \multirow{2}{*}{ Juan Carlos Vera Báez (ANR) } \\
\hline & PLRA & 26,64 & \\
\hline \multirow{2}{*}{ Caaguazu } & Ganar & 46,17 & \multirow{2}{*}{ Alejo Ríos Medina (Ganar) } \\
\hline & ANR & 44,58 & \\
\hline \multirow{2}{*}{ Caazapa } & ANR & 49,84 & \multirow{2}{*}{ - Pedro Alejandro Díaz Verón (ANR) } \\
\hline & Ganar & 41,49 & \\
\hline \multirow{2}{*}{ Itapua } & ANR & 44,39 & \multirow{2}{*}{ Juan Alberto Schmalko Palacios (ANR) } \\
\hline & Ganar & 39,62 & \\
\hline \multirow{2}{*}{ Misiones } & ANR & 48,29 & \multirow{2}{*}{ - Carlos María Arrechea Ortiz (ANR) } \\
\hline & Ganar & 44,23 & \\
\hline \multirow{2}{*}{ Paraguari } & ANR & 46,03 & \multirow{2}{*}{ - Juan Carlos Baruja Fernández (ANR) } \\
\hline & Ganar & 37,18 & \\
\hline \multirow{2}{*}{ Alto paraná } & ANR & 37,34 & \multirow{2}{*}{ Roberto Luis González Vaesken (ANR) } \\
\hline & Ganar & 31,64 & \\
\hline \multirow{2}{*}{ Central } & ANR & 44,00 & \multirow{2}{*}{ Hugo Javier González Alegre (ANR) } \\
\hline & PLRA & 42,12 & \\
\hline \multirow{2}{*}{ Neembucu } & ANR & 47,76 & \multirow{2}{*}{ - Luis Federico Benítez Cuevas (ANR) } \\
\hline & PLRA & 45,95 & \\
\hline \multirow{2}{*}{ Amambay } & PLRA & 48,08 & \multirow{2}{*}{$\begin{array}{l}\text { Ronald Enrique Acevedo Quevedo } \\
\text { (PLRA) }\end{array}$} \\
\hline & ANR & 44,40 & \\
\hline \multirow{2}{*}{ Canindeyu } & ANR & 53,12 & \multirow{2}{*}{ César Ramírez Caje (ANR) } \\
\hline & Ganar & 34,26 & \\
\hline
\end{tabular}




\begin{tabular}{llrl}
\hline \multicolumn{1}{c}{ Defartamento } & \multicolumn{1}{c}{ Partido } & \% voto & Gobernador Electo \\
\hline \multirow{2}{*}{ Pdte. Hayes } & ANR & 32,29 & Rubén Antonio Roussillon Blaires (ANR) \\
\cline { 2 - 3 } & Ganar & 21,10 & \\
\hline \multirow{2}{*}{ Alto paraguay } & ANR & 49,10 & José Domingo Adorno Mazacotte (ANR) \\
\cline { 2 - 3 } Boqueron & Ganar & 43,69 & \\
\hline \multirow{2}{*}{ ANR } & 49,33 & Darío Rafael Medina Velázquez (ANR) \\
\cline { 2 - 4 } & Ganar & 34,67 & \\
\hline
\end{tabular}

Fuente: elaboración propia a partir de datos del Tribunal Superior de Justicia Electoral (TSJE)

Sin excepción, todos los gobernadores electos son de sexo masculino, habiendo incluso una gran cantidad de departamentos en los que ni siquiera existió una candidata mujer ${ }^{28}$.

\section{COYUNTURA ECONÓMICA Y DESARROLLO SOCIAL: FENÓMENOS DINÁMICOS EN FRICCIÓN}

\section{Cuentas nacionales y breve panorama macroeconómico}

En el Informe de Política Monetaria, el Banco Central de Paraguay (всР) caracterizó la primera mitad de 2018 como un momento de dinamismo en la economía doméstica, mientras la segunda mitad moderó su crecimiento, sobre todo por las limitaciones que atraviesan los países vecinos, que impactan fuertemente en el equilibrio monetario y económico del Paraguay.

Según el Informe de Inflación del вСР, la inflación para enero de 2018 fue de 0,8 \%, según el Índice de Precios al Consumidor (IPC), mostrando un aumento de $0,2 \%$ en comparación a la tasa registrada en el mismo mes del año anterior. Para diciembre de 2018, la inflación medida según la variación del IPC fue de $-0,3 \%$, inferior al 0,5\% del mismo período de 2017 .

La inflación fue controlada, no presentó dificultades macro ni microeconómicas y se desarrolló en torno al precio de los alimentos, bienes y servicios de primera necesidad. Es por esto que la caída de diciembre se debió a la disminución de cortes cárnicos y de otros productos alimenticios. Esto explica que la inflación de los bienes de la canasta fue del $0,6 \%$ en diciembre. Según el informe del Banco Mundial, publicado en junio de 2018, Paraguay presenta un crecimiento económico sólido y sostenido, con una fuerte reducción de la pobreza y con una macroeconomía estable por varios años. La inflación y la deuda pública son especialmente bajas. Sus potenciales económicos son la tierra y las 
hidroeléctricas. Sin embargo, Paraguay también presenta: a) una muy alta concentración de ingresos, ganancias, producción, exportación e influencia política, reducidos a un conjunto muy pequeño de actores económicos; b) una prevalencia de relaciones económicas informales; y c) un deficitario sistema de servicios públicos (Banco Mundial 2018).

A partir de datos del вСР (2018), podemos confirmar que el crecimiento del PIB se muestra positivo en su variación anual y que las cuentas nacionales muestran un equilibrio potencialmente inestable por la dependencia de factores externos, pero sostenido por el momento, incluso en situación de retracción regional. La tabla 6 muestra la variación interanual en porcentajes del crecimiento sectorial del PIB.

Tabla 5. Crecimiento económico y cuenta corriente.

Variación anual en porcentaje (2017 y 2018)

\begin{tabular}{lrr}
\hline & 2017 & 2018 \\
\hline PIB & 5,0 & 4,0 \\
Demanda interna & 5,9 & 4,6 \\
Formación bruta de capital & 12,7 & 4,5 \\
Formación bruta de capital fijo & 5,9 & 4,5 \\
Consumo total & 4,2 & 4,7 \\
Consumo privado & 4,5 & 4,4 \\
Consumo público & 2,1 & 6,5 \\
Exportación de bienes y servicios & 8,3 & 4,5 \\
Importación de bienes y servicios & 12,0 & 6,5 \\
Cuenta corriente (\% del pIB) & 3,1 & 0,7 \\
\hline FBKF (\% del PIB nominal) & 18,6 & 18,7 \\
\hline
\end{tabular}

Fuente: Banco Central del Paraguay. Informe 2018

La presión tributaria sigue siendo baja a nivel regional, con un incremento muy lento y gradual. Esta es una de las solicitudes del Banco Mundial, instancia que, en su Diagnóstico de 2018, señaló que la carga de impuestos es aún insuficiente, lo que impacta en la conformación del Estado y en el aparato público administrativo disponible, que es muy pequeño, e influyendo negativamente en la capacidad estatal de proveer servicios sociales y mejorar la infraestructura ${ }^{29}$.

29 El documento original cita: "The low tax base has translated into a small public administration apparatus: the share of revenues and expenditures as percentage of GDP is slightly above 20 percent (not including the SOE sector), well below the OCDE average and that of regional peers. This in turn has limited the ability of 
Además, las actividades del sector primario aportan muy poco al fisco, siendo una de las más dinámicas del país. En el 2018, el всР modificó el año base de sus cuentas nacionales. A partir de información compensada al 2014 de la Subsecretaría de Estado de Tributación (SET) y del всP, queda evidenciado que mientras la actividad primaria significa el 12\% aproximado del PIв (para 2017), su aporte tributario no excede el $6 \%$.

Según la línea histórica de recaudación de impuestos de la SET, mientras que el IVA derivado de actividades industriales, comerciales y de servicios significó 6 281457 millones de guaraníes en 2018, el del sector agropecuario fue apenas de 403123 millones de guaraníes (SET 2019).

La recaudación por el Impuesto a la Renta Comercial, Industrial o de Servicios (IRACIS) fue de 4524063 millones de guaraníes, mientras que el total del Impuesto a la Renta de Actividades Agropecuarias (IMAGRo) y el Impuesto a la Renta de las Actividades Agropecuarias (IRAGRO) fue de 360003 millones de guaraníes (SET 2019).

Tabla 6. Presión tributaria en millones de guaraníes y porcentaje (2014-2018)

\begin{tabular}{rrrr}
\hline AÑo & $\begin{array}{c}\text { INGRESOS } \\
\text { TRIBUtARIOS }\end{array}$ & PIB (AÑO BASE 2014) & $\begin{array}{r}\text { PresióN } \\
\text { TRIBUTARIA \% }\end{array}$ \\
\hline 2014 & 17409920,0 & 179721609,0 & 9,7 \\
2015 & 18008265,0 & 188203723,0 & 9,6 \\
2016 & 19439538,0 & 204447278,0 & 9,5 \\
2017 & 21694678,0 & 219188417,0 & 9,9 \\
2018 & 23081073,0 & $231046521 *$ & 10,0 \\
\hline
\end{tabular}

Fuente: elaboración propia en base a datos del Banco Central del Paraguay (вср), Subsecretaría de Estado de Tributación (SET) y Dirección Nacional de Aduanas (DNA)

*El PIB de 2018 es proyectado

El Diagnóstico del Banco Mundial (2018) señaló que el crecimiento económico es muy favorable, no obstante, solo podrá satisfacer las necesidades de la sociedad cuando se convierta en un modelo inclusivo y sustentable.

\section{Impacto social de la matriz productiva y económica}

Respecto de la convergencia entre este desarrollo económico y el impacto social, son clave los datos provistos por la Dirección General de Estadísticas, Encuestas y Censos (DGEEC) y su informe sobre la calidad de vida en $2018^{30}$.

the state to deliver effectively a range of public social services and also upgrade the infrastructure of the country" (Banco Mundial 2018).

30 La EPHC de 2018 modificó la base de encuestados, disminuyéndola de 11412 viviendas en 2017 a menos de cinco mil viviendas efectivamente entrevistadas en 2018. Esto generó un cambio en la confiabilidad, razón 
El informe de Pobreza Monetaria de la EPHC-2018 (DGEEC 2019), publicado en marzo de 2019, demostró que, a pesar de su crecimiento sostenido, aún existe en Paraguay un 4,8 \% de pobreza extrema, superior al 4,4 \% registrado en 2017, aunque sigue siendo menor que los años anteriores. La pobreza extrema rural alcanza el $10 \%$, mientras la urbana es de 1,6\%. En cuanto a la pobreza total, se registró un $24,2 \%$ de la población en esta situación, siendo el número más bajo desde 1997, habiendo pasado por picos de $57,7 \%$ en 2002. Sin embargo, al analizar el fenómeno a partir de las áreas de residencia, encontramos que la pobreza total en el área rural es de 34,6 \% y en la urbana 17,8\%. Estos datos pueden verse alterados por la diferencia de la confiabilidad de la EPHC-2018 (DGEEC 2019).

Referido al empleo, la EPHC-2018 (DGEEC 2019), mostró que el desempleo creció al 5,7 \%, afectando especialmente a las mujeres con un 6,8 \%. En 2017, el desempleo fue de 5,2 \%. El subempleo visible pasó de 5,4\% en 2017 a 5,9\% en 2018. Sin embargo, por el cambio metodológico, estas diferencias con el año previo son irrelevantes estadísticamente y no permiten comparaciones.

El porcentual de analfabetismo en personas mayores de 15 años sigue subiendo desde 2015, cuando alcanzó un 4,4 \%, llegando en 2018 a 6 \% EPHC 2018 (DGEEC 2019). Respecto del aporte al sistema de jubilación, este llegó al 44,8 \%, el porcentaje más alto registrado. Sin embargo, sigue siendo sustancialmente deficitario, dado que no cubre ni siquiera a la mitad de la población ocupada (DGEEC 2019).

En 2018, con la intención de influir sobre la diversidad de las cajas de aportes y ahorros programados, se debatió el proyecto de ley "Que crea el Consejo Asesor del Sistema Nacional de Jubilaciones y Pensiones, la Superintendencia de Jubilaciones y Pensiones, y establece normas de inversión del Sistema de Jubilaciones y Pensiones", presentado en 2015. El fin de la ley era estudiar el sistema nacional de pensiones, creando medidas tendientes a su integración y mayor alcance, así como fiscalizar el funcionamiento de los fondos de pensión para reducir los riesgos de las inversiones. La ley apuntaba también a la constitución de un consejo asesor y de una superintendencia para auditar cajas y fondos. El 10 de octubre de 2018, la Cámara de Diputados impugnó la propuesta, tras el rechazo en el Senado.

Retomando el análisis de la calidad de servicios públicos y derechos, nos interesa remarcar que solo el $26,9 \%$ de la población cuenta con cobertura de seguro médico (DGEEC 2019). El resto de la población se atiende en el sistema público de salud, que se encuentra fuertemente desfinanciado y con carencias de suministros y drogas. El porcentaje declarado por Paraguay destinado a la salud es del 7 \% (Cepal 2018). 
Por su parte, en cuanto a educación, Cepal (2018) muestra que la tasa neta de matrícula en educación primaria en Paraguay (inscripciones en el año 2017) es la más baja de la región. De hecho, con un 78,0 \% Paraguay está muy por debajo de la media latinoamericana y caribeña, que es 93,1 \%. Algo similar ocurre para el nivel secundario, donde, según el mismo reporte, la tasa alcanza solo el 64,9 $\%$, siendo, el promedio regional, 76,9\%. Solo tienen una menor tasa neta de matrícula a la escuela secundaria El Salvador, Guatemala y Honduras (Cepal 2018).

Respecto de la cobertura de los programas sociales Tekopora y Pensión para Adultos Mayores ${ }^{31}$, se confirma que la población beneficiaria se mantiene estable. Siguiendo a Bruno (2018), el impacto de la pensión para adultos mayores en la calidad de vida de las personas beneficiarias es significativo. El autor indica que, en caso de dejar de percibir el ingreso, alrededor de un $10 \%$ de la población target de la política caería dentro de la pobreza. Si bien esto responde a datos de 2016, la tendencia se mantiene hasta la actualidad. La tabla 7 nos permite observar la presencia que tienen estos programas en los sectores más vulnerables económicamente, correspondientes al primer y segundo quintil de ingreso per cápita mensual.

Tabla 7. Principales indicadores de programa social (Tekopora y Adultos Mayores) de la población por año en porcentajes (2016-2018)

\begin{tabular}{lccc}
\hline & 2016 & 2017 & 2018 \\
\hline $\begin{array}{l}\text { Población del Q1 cuyos hogares son cubiertos con } \\
\text { algún programa social }\end{array}$ & 34,2 & 36,5 & 36,2 \\
$\begin{array}{l}\text { Población del Q2 cuyos hogares son cubiertos con } \\
\text { algún programa social }\end{array}$ & 20,5 & 22,7 & 26,8 \\
\hline
\end{tabular}

Fuente: elaboración propia en base a DGEEC $(2016,2017,2018$ y 2019)

\section{CAMPO SOCIAL Y ORGANIZACIONES POPULARES. ENTRE LAS TRAYECTORIAS DE LUCHA Y SOBREVIVIR A LA REPRESIÓN}

El contexto social paraguayo estuvo caracterizado por las marchas en contra de los funcionarios y congresales involucrados en casos de corrupción. Siguiendo a Duarte Recalde y González Ríos (2016), afirmamos que las trayectorias de

31 Recordemos que ambos programas tienen como finalidad asistir a grupos sociales vulnerables. El programa Tekopora, iniciado en 2005, convertido en programa emblemático en 2009, busca mejorar la calidad de vida de la población en entornos de pobreza y extrema pobreza, pensando en hogares vulnerables y excluidos socialmente. Incentiva, además, la contraprestación de cuidados alimenticios, también de salud y educación. Por su parte, la pensión para adultos mayores, vigente desde 2009, está dirigida a personas en situación de pobreza de sesenta y cinco años o más. 
protesta y la organización social presentaban articulaciones exitosas desde años anteriores. Para 2015, las autoras exponían: "dentro de un marco de desaceleración económica, la participación política no convencional ganó fuerza de la mano de movilizaciones sociales que evidenciaron mayor capacidad de la ciudadanía paraguaya para articular sus reclamos y alcanzar objetivos colectivos" (Duarte Recalde y González Ríos 2016: 287).

En 2018, la sociedad se vio atravesada por un recrudecimiento de los enfrentamientos entre bandas narcotraficantes, lo que aumentó los atentados y asesinatos por sicariato. Marcelo Pinheiro Veiga, uno de los líderes del grupo criminal brasileño Comando Vermelho, con fuerte presencia en territorio paraguayo, protagonizó otro sangriento episodio, asesinando, dentro de la cárcel en la que se encontraba recluso por tráfico de drogas, a una joven paraguaya que se acercó a visitarlo. Esto reveló la precariedad y el poco control existente al interior de las unidades penitenciarias.

La guerra narco activó enfrentamientos en diferentes ciudades y fue el centro de la escena mediática y política.

Por su parte, respecto de los movimientos campesinos y sus repertorios de resistencia, se vivenció un vuelco en la causa judicial por la Masacre de Curuguaty, ocurrida en 2012. En 2018, la justicia paraguaya decidió revocar la sentencia a los campesinos culpados por el suceso desencadenante del juicio político a Fernando Lugo Méndez. Al respecto, el Informe de Derechos humanos de la codehupy (2018) explica que la sentencia revirtió un caso de injusticia y persecución violentas que no había sostenido la pena en ninguna evidencia certera, sino en ensañamiento contra los actores campesinos ${ }^{32}$. Es necesario agregar que los tres magistrados que declararon la libertad de los campesinos apresados por procesos viciados fueron denunciados por la fiscala general del Estado, Sandra Quiñónez, por "mal desempeño de sus funciones" tras desacordar con su decisión.

La lógica de muerte en ataques fugaces, generalmente en vehículos andando, no se limitó a los ajustes de cuentas entre bancas traficantes, también ha cobrado víctimas entre los líderes de movimientos campesinos que, como explicó el informe Chokokue 1989-2013 (2014), son selectivamente asesinados por sicarios, práctica represiva que se mantiene hasta la actualidad. Este fue el caso de María Ester Riveros, prima de María Máxima Segovia, reconocida lideresa

32 “La sentencia de los magistrados de cámara de apelación, Emiliano Rolón Fernández, Arnaldo Martínez Prieto y Cristóbal Sánchez — quienes, por inhibición de los ministros de la Corte Suprema de Justicia, tuvieron que integrar su Sala Penal para resolver la casación en el caso Curuguaty- es particularmente relevante. Al tiempo de confirmar las denuncias sobre la inobservancia del debido proceso — que fueron señaladas por numerosos observadores-, en sí mismas, dichas resoluciones constituyen una crítica razonada de la máxima instancia judicial hacia los fiscales intervinientes. Estos, a pesar de no haber logrado destruir el estado de inocencia de los inculpados e inculpadas, igualmente llevaron adelante una acusación carente de fundamento - como en muchos otros casos-, hasta lograr una alta condena, al calor y en el contexto político hostil para las personas sometidas a juicio, que desde un comienzo condicionó el actuar judicial" (CODEHUPY 2018: 561). 
del movimiento de campesinos de Canindeyú, quien reconoce que el asesinato de su familiar fue, en realidad, por error, pues los sicarios preguntaron por ella. Riveros fue la primera mujer campesina en morir en el contexto de la lucha por la tierra, que ya se ha cargado la vida de más de ciento veinte campesinos.

Desde otro frente, el movimiento guerrillero autodenominado Ejército del Pueblo Paraguayo (EPP) ${ }^{33}$ ejecutó un conjunto de acciones, mostrando que las Fuerzas de Tarea Conjunta, fuerza elite revitalizada y sobrefinanciada por el gobierno de Horacio Cartes, no podían cumplir con la promesa de eliminar el foco de guerrilla ${ }^{34}$.

En cuanto a los trabajadores urbanos, quisiéramos rescatar una experiencia específica en el contexto de lucha sindical: la organización e incidencia política de los sindicatos de empleadas domésticas, quienes lograron —en 2018- que se debata la ley de 2016 por la que requerían ser beneficiarias como piso, del pago del total del salario mínimo. Estas trabajadoras, desde el 2015, ganaban solo el $60 \%$ del salario mínimo (20\% más que antes), por lo que reclamaron llegar a la totalidad de referencia. Luego de muchas acciones, de articulación con el movimiento feminista nacional y regional y de coordinación de acciones con organizaciones no gubernamentales (ONG), lograron el 70 \% del mínimo. Recién en 2019 accedieron al mismo derecho que cualquier otro trabajador, cuando el Senado aprobó el reconocimiento del 100\% del salario mínimo para ellas.

\section{BREVE PANORAMA DE PARAGUAY EN CONTEXTO REGIONAL E INTERNACIONAL}

En su informe sobre la situación regional de diciembre de 2018, el Banco Central de Paraguay expresa su preocupación por la condición económica y productiva que se atraviesa a escala global y regional ${ }^{35}$. Agrega que la situación se encuentra mejor por el incremento del PIB brasilero y su repunte económico, pero que las expectativas de crecimiento regional para 2018 se revisaron a la baja. En cuanto a Argentina, el órgano central de la economía paraguaya se mostró preocupado por la debilidad de sus condiciones económicas y financieras (Banco Central de Paraguay 2018).

33 Recomendamos la lectura de Nickson (2018) para analizar el caso del EPP.

34 Es interesante el abordaje de Martens y Estigarribia (2018: 69) sobre las políticas de mano dura en Paraguay: "los hallazgos indican que las políticas de mano dura no son eficaces para el control de la delincuencia y se debe apostar a las de inclusión social, certeza jurídica, disminución de la impunidad y control constitucional de la selectividad punitiva". Nos resulta también importantes los trabajos de Solís, Cerna y Peris (2019) para entender el fenómeno de la violencia letal en Paraguay.

35 El documento cita: "Las tensiones comerciales entre Estados Unidos y China, el endurecimiento de las condiciones financieras, la volatilidad en los mercados bursátiles internacionales y factores idiosincráticos de cada país, han incrementado la incertidumbre a nivel global" (Banco Central de Paraguay 2018: 5). 
Esto demuestra la vulnerabilidad de la economía paraguaya a los factores externos, también evidente en la importancia de las commodities y la exportación agropecuaria en el PIB nacional ${ }^{36}$.

En cuanto al perfil internacional, Paraguay tuvo un rol importante en la conformación en 2017 del Grupo de Lima y obtuvo protagonismo en 2018 por anunciar un conjunto de medidas tendientes a suspender su relación con Venezuela. En mayo, fue el encargado de transmitir al gobierno venezolano que el Grupo de Lima no aceptaría el resultado de sus comicios. Además, anunció la reducción progresiva de las relaciones diplomáticas entre ambos Estados, llegando a la ruptura total en enero de 2019. Esto respondió a un cambio en el abordaje de las relaciones exteriores de Paraguay, alejándose de las uniones regionales, tendencia que culminó con el retiro del país de la Unasur en 2019.

Antes de dejar la presidencia, Horacio Cartes selló con su par argentino Mauricio Macri un acuerdo por la represa binacional Yacyreta, que retomó la Nota Reversal de 1992. Esto reviste fundamental importancia para el país, puesto que los ingresos por las hidroeléctricas son nodales. El acuerdo de 2018 fue fuertemente resistido por especialistas de la temática, también por algunos miembros del Congreso, por cederle derechos a Argentina y aceptar el 50\% de las obligaciones sobre una deuda de la que Paraguay declaró no haber tenido responsabilidad ni uso. Sin embargo, pasó la votación en el Congreso por la mayoría y las articulaciones que el cartismo logró condensar. Al asumir la presidencia, Mario Abdo Benítez nombró a la cabeza de Cancillería al colorado Luis Alberto Castiglioni Soria, ingeniero con una larga carrera política como congresal, llegando a ser vicepresidente entre 2003 y 2007, bajo la presidencia de Nicanor Duarte Frutos, líder cercano a Abdo.

Entre las primeras medidas tomadas por Castiglioni en 2018, debemos mencionar la de revertir la decisión tomada por el gobierno de Horacio Cartes de mudar la Embajada de Paraguay en Israel desde Tel Aviv a Jerusalén. La medida cartista había generado un conjunto de debates en el Congreso, que, a pesar de no tener potestad ni injerencia en la temática, subrayó el peligro que esta decisión significaba en el equilibrio de las relaciones internacionales paraguayas. Los reclamos también llegaron desde el presidente electo, dado que Cartes tomó esta decisión cuando Abdo ya había sido elegido, y de manera inconsulta.

Cuando Castiglioni reemplazó al canciller de la gestión anterior, Eladio Loizaga, y desanduvo el camino, declaró oficialmente que, al anular este cambio de sede, "la República del Paraguay reafirma su vocación de mantener excelentes vínculos de amistad y cooperación con los Estados de Israel y Palestina, basados en principios y valores compartidos" (Cancillería 2018). En una de sus

36 Esto puede observarse en la versión oficial que sostiene: “con respecto a la economía doméstica, el dinamismo observado en la primera mitad del año, se moderó en los últimos meses, explicado en parte, por el entorno regional más complejo, como así también por algunos factores internos de oferta" (Banco Central de Paraguay 2018: 7). 
intervenciones mediáticas, Castiglioni sostuvo: “Esta decisión fue tomada por el gobierno anterior en una actitud unilateral e inconsulta y sin ningún tipo de argumentos fundados en el derecho internacional. Fue una decisión, diría, yo, hasta visceral" (2018).

\section{CONCLUSIONES}

A lo largo de este artículo hemos presentado una multiplicidad de sucesos políticos, sociales, económicos y de contexto regional, con la intención de proveer un panorama complejo del 2018 como momento histórico del Paraguay. Los fenómenos que describimos surgen de un proceso desarrollado durante varios años. Muchos — de gran relevancia - han quedado afuera, pues hemos seleccionado solo algunos, en función de una decisión metodológica y, también, personal.

Las elecciones generales fueron el eje central del desarrollo político, sin embargo, también pudimos repasar: 1) cómo se logró el acceso de una mujer a la vicepresidencia por primera vez en la historia del país, aunque esto no haya redundado en una mayor democratización ni igualdad en el acceso a cargos políticos por parte de las mujeres; 2) las particularidades de las disputas internas de la ANR, que tiñeron el escenario político en varias esferas y niveles; 3) la reedición de la alianza opositora al coloradismo que no pudo quedarse con el Poder Ejecutivo, no obstante continuó con la práctica de la conformación de coaliciones que parecía difícil de reeditar tras el fracaso de la Alianza Patriótica para el Cambio, en el contexto de la remoción de Fernando Lugo en 2012 y el enfrentamiento en torno a la reelección de 2017; y 4) el impacto generado por la corrupción y su puesta en evidencia, sobre todo en un sector social que tomó la causa como propia e inauguró un formato de protesta que logró forzar la renuncia de algunos miembros de la elite política.

En la contienda electoral, el Partido Colorado reafirmó su hegemonía, aunque la diferencia de votos obtenida con su contrincante prioritario, la Alianza Ganar, fue una de las más bajas de la historia. Otro rasgo visible de estas elecciones es la falla en las medidas tendientes a la participación política de mujeres, dado que accedieron a un número muy minoritario de escaños y a ninguna gobernación.

La economía se mostró estable y apenas más retraída que lo proyectado, sobre todo por la situación regional de decrecimiento marcado prioritariamente por Argentina. La matriz productiva es fuertemente agroganadera y sus actores tributan muy poco al fisco, lo cual genera una negativa retroalimentación con el Estado y la sociedad. El primero no puede desarrollar una burocracia apta y eficiente y la segunda está cargada con impuestos regresivos para revertir el desfinanciamiento público. 
En términos regionales, Paraguay dio por cerrado un período de alianzas con los países vecinos, disminuyendo el esfuerzo integracionista del Mercosur y retirándose de Unasur en 2019.

Respecto al escenario social y de derechos humanos, encontramos, al menos, tres grandes problemas: 1) la presencia de bandas criminales y narcotraficantes con sus propios enfrentamientos facciosos, sobre los que el Estado no ha podido mostrarse eficiente ni en la prevención ni en la sanción; 2) las prácticas arraigadas, a lo largo de todo el período, de asesinato por sicariato a líderes de movimientos campesinos, su persecución política y judicial y el constante accionar estatal violento en contra de sus asentamientos y campamentos de ocupación de tierras; y 3) la militarización del espacio público, con el argumento de detener los peligros de una supuesta guerrilla y de otros grupos criminales, que han llevado a un aumento de la tortura, la doctrina de "mano dura", la represión y la persecución selectiva, sin disminuir los casos de inseguridad.

La democracia paraguaya tiene, hoy, más desafíos que certezas. Eso no constituye, per se, un mal político. De hecho, la complejización de las sociedades tiende a interpelar la calidad democrática y a poner en jaque sus instituciones, que deben reinventarse y equilibrarse entre lo dinámico de la política y lo estático de los procesos burocráticos.

Resultan necesarias modificaciones en: 1) el sistema de previsión social, con el fin de generar una universalización de sus prestaciones; 2) las condiciones laborales, para disminuir el trabajo informal; 3) los índices de pobreza (total y extrema), para que su disminución sea paulatina y se correlacione con el aumento de la economía; y 4) el respeto por los derechos humanos, tanto en los referidos a salud, vivienda, educación de calidad, como a los concernientes al derecho a la vida y el ejercicio de los derechos políticos.

\section{REFERENCIAS}

Abdo Benítez, Mario. 2018, 15 de agosto. “Discurso de asunción al cargo de Presidente de la República". Recuperado el 22 de septiembre de 2018 de www.presidencia.gov.py

Bruno, Sebastián. 2018. "Impacto redistributivo de la pensión alimentaria para adultos mayores en situación de pobreza (Paraguay)". Revista MERCOSUR de Políticas Sociales 2: 265-286.

Cancillería de Paraguay. 2018, 5 de septiembre. “Comunicado sobre la ubicación de la Embajada de la República del Paraguay ante el Estado de Israel. Publicación oficial". Recuperado el 16 de febrero de 2019 de http://www2.mre.gov.py/index.php/noticias/ comunicado-sobre-la-ubicacion-de-la-embajada-de-la-republica-del-paraguay-ante-el-estado-de-israel

Carrizosa, Andrés. 2018. “Paraguay 2017: competencia política en las Cámaras, en las calles y en las urnas". Revista de Ciencia Política 38 (2): 335-360.

Cartes, Horacio. 2018, 26 de junio. "Veo con gran pena que algunos legisladores no desean que se cumpla la voluntad popular del 22 de abril, por lo que retiro mi renuncia al cargo de Presidente de la República. Lamento que entre colorados no pudimos llegar con una 
bancada unida al próximo periodo" [Tuit. 26 de junio. Cuenta oficial]. Recuperado el 9 de marzo de 2019 de https: / / twitter.com/Horacio_Cartes

Cartes, Horacio. 2018, 26 de junio. "Retiro oficial de renuncia". Nota oficial.

Cartes, Horacio. 2018, 28 de mayo. "Renuncia oficial al cargo de Presidente de la República". Nota oficial.

Centurión, Griselda. 2019, 4 de febrero. "Un clan, dos imputaciones. El fin de un 'reinado feliz'". Recuperado el 19 de mayo de 2019 de http://www.abc.com.py/edicion-impresa/suplementos/judicial/el-fin-de-un-reinado-feliz-1783674.html

Cepal. 2019, marzo. "Anuario estadístico de América Latina y el Caribe 2018". Recuperado el 12 de abril de 2019 de https:/ / www.cepal.org/es/publicaciones/44445-anuario-estadistico-america-latina-caribe-2018-statistical-yearbook-latin

Código Electoral Paraguayo. Ley No. 834/96. Recuperado el 12 de octubre de 2018 de http:/ / tsje.gov.py/static/ups/legislaciones/1996-ley-834.pdf

Constitución Nacional de Paraguay, 1992. Asunción: Tribunal Superior de Justicia Electoral.

Cubas, Paraguayo. 2019, 1 de abril. Proyecto de Ley "Que modifica el artículo 258 de la Ley No. 834/96 'Que establece el Código Electoral Paraguayo', y su modificatoria Ley No. $5350 / 14$ ', Derogación del Desbloqueo (Ley No. 4584/12", presentado por el Senador Paraguayo Cubas. Recuperado el 15 de abril de 2019 de http:/ / silpy.congreso.gov.py / expediente/115916

Dgeec. 2019, marzo. "Encuesta permanente de hogares. Período 2018”. Recuperado el 20 de marzo de 2019 de www.dgeec.gov.py

Dgeec. 2018, marzo. "Encuesta permanente de hogares. Período 2017". Recuperado el 12 de marzo de 2019 de www.dgeec.gov.py

Dgeec. 2017, marzo. "Encuesta permanente de hogares. Período 2016". Recuperado el 27 de febrero de 2019 de www.dgeec.gov.py

Dgeec. 2016, marzo. "Encuesta permanente de hogares. Período 2015". Recuperado el 27 de febrero de 2019 de www.dgeec.gov.py

Duarte Recalde, Liliana Rocío y Cynthia González Ríos. 2016. "Paraguay: entre las movilizaciones sociales y el reordenamiento electoral". Revista de Ciencia Política 36 (1): 297-312.

Duarte Recalde, Liliana Rocío. 2013. "Comportamiento electoral en el Paraguay a nivel departamental". Revista Paraguay desde las Ciencias Sociales 2: 26-44.

Duarte Penayo, José. 2018, 29 de octubre. "Paraguayo Cubas: ¡son las formas, estúpido!". Recuperado el 12 de marzo de 2019 de: https:/ / tererecomplice.com/2018/10/29/paraguayo-cubas-son-las-formas-estupido/\#more-1506

González Bozzolasco, Ignacio. 2017. "Paraguay: la reelección presidencial y los inicios de la carrera electoral 2018". Revista de Ciencia Política 37 (2): 543-562.

Informe Chokokue 1989-2013. 2014, 20 de marzo. "El plan sistemático de ejecuciones en la lucha por el territorio campesino".. Recuperado el 10 de enero de 2019 de http:/ / codehupy.org.py/wp-content/uploads/2013/03/INFORME-CHOKOKUE-1989-2013.pdf

Informe de Inflación. 2019, enero. "Banco Central del Paraguay. Período: de enero a diciembre 2018". Recuperado el 12 de febrero de 2019 de https://www.bcp.gov.py/informe-de-inflacion-mensual-i362

Informe de Política Monetaria. 2019, enero. “Banco Central del Paraguay. Período: diciembre 2018". Recuperado el 12 de febrero de 2019 de https://www.bcp.gov.py/informe-de-politica-monetaria-i14

Lachi, Marcello. 2018. "Las penas del joven Horacio: de la crisis del Nuevo Rumbo y de cómo sobrevivir a las múltiples derrotas". Revista NOVAPOLIS 13: 67-92.

López, Magdalena. 2018. Transición y democracia en Paraguay (1989-2017). El cambio no es una cuestión electoral. Buenos Aires: Editorial sв.

López, Magdalena. 2017. "Por el bien del pueblo que a través de mí gobierna: reflexiones en torno a la teoría de la representación democrática a partir del impeachment paraguayo y brasileño". En Novas Epistemes e narrativas contemporáneas, organizado por Aguinaldo Rodrigues Gomes, Marcos Antonio De Menezes y José González. Campo Grande: Life-Editora, 159-191. 
Martens, Juan Alberto y Rodrigo Estigarribia. 2018. “Eficacia de las políticas de mano dura en Paraguay. Análisis a partir de datos objetivos de inseguridad en Asunción, Central y Amambay 2010-2016". Revista Jurídica Investigación en Ciencias Jurídicas y Sociales 7: 43-74.

Nickson, Andrew. 2018. "Revolutionary Movements in Latin America after the Cold War: The Case of the Ejército del Pueblo Paraguayo". Bulletin of Latin American Research. DOI: 10.1111/blar.12851: 1-16.

Pérez Talia, Marcos. 2018. “Elecciones en Paraguay. El Partido Colorado se eterniza en el poder". Foreign Affairs Latinoamerica 18 (4): 45-52.

Proyecto de Ley 543/2017. 2017, 4 de abril. "Que crea el Consejo Asesor del Sistema Nacional de Jubilaciones y Pensiones, la Superintendencia de Jubilaciones y Pensiones, y establece normas de inversión del Sistema de Jubilaciones y Pensiones". Recuperado el 15 de abril de 2019 de http:/ / silpy.congreso.gov.py/expediente/109184

Ruiz Díaz, Estela. 2018, 28 de octubre. "Payo, un síntoma que pone en la mira la perversa política". Recuperado el 12 de enero de 2019 de https://www.ultimahora.com/payo-un-sintoma-que-pone-la-mira-la-perversa-politica-n2776044.html

Solís Delgadillo, Juan M. y Sarah P. Cerna Villagra. 2019. “Fricción, (re)concentración y afianzamiento conservador tras las elecciones de 2018 en Paraguay". Estudios Políticos (Universidad de Antioquia) 54: 259-285.

Solís Delgadillo, Juan M., Sarah P. Cerna Villagra y Carlos A. Peris Castiglioni. 2018. “QQué explica la violencia letal en Paraguay? Un estudio con intención comparativa". Revista Perfiles Latinoamericanos 27 (53): 1-26.

Subsecretaría de Estado de Tributación (SET). 2019, marzo. "Recaudación por impuestos 20102019". Recuperado el 24 de marzo de 2019 de https: / www.set.gov.py/portal/PARAGUAY-SET/Home/est?folder-id=repository:collaboration:/sites/PARAGUAY-SET/ categories/SET/Estadistica/recaudaciones-tributarias

Tribunal Superior de Justicia Electoral (TSJE). 2008. Resultados de las votaciones generales de 2008. Recuperado el 20 de enero de 2019 de https://www.tsje.gov.py/e2008/ pdf/2008.pdf

Turner, Brian. 2014. "Paraguay: la vuelta del Partido Colorado al poder". Revista de Ciencia Política 34 (1): 249-266.

World Bank Group. 2018, 27 de junio. "Paraguay. Systematic Country Diagnostic. Período: 2018". Recuperado el 23 de marzo de 2019 de http://documents.worldbank.org/curated/en/827731530819395899/Paraguay-Systematic-Country-Diagnostic

Recibido: 15 de abril de 2019

Aceptado: 27 de mayo de 2019

Magdalena López. Licenciada en Ciencia Política y Doctora en Ciencias Sociales por la Universidad de Buenos Aires (UBA). Investigadora de CONICET con sede en el Instituto de Investigaciones Gino Germani (IIGG, UBA) y coordinadora del Grupo de Estudios sociales sobre Paraguay (GESP) en el Instituto de Estudios de América Latina y el Caribe (IEALC, UBA). Se caracteriza por un abordaje multidisciplinario donde confluyen elementos de la teoría política, la sociología y la ciencia política. E-mail: magui@sociales.uba.ar 